\title{
LABORATORY STUDIES OF PLANETARY MOLECULES AND ICES: THE CASE OF IO
}

\author{
F. SALAMA, S.A. SANDFORD, and L.J. ALLAMANDOLA \\ NASA-Ames Research Center. Space Science Division, MS: 245-6 \\ Moffett Field, CA 94035, U.S.A
}

\begin{abstract}
The techniques of low temperature spectroscopy are applied here to analyze infrared observational data of Io in the $2.0-5.0 \mu \mathrm{m}$ range. The presence of solid $\mathrm{H}_{2} \mathrm{~S}$ and traces of $\mathrm{H}_{2} \mathrm{O}$ in the $\mathrm{SO}_{2}$-dominant surface ices are derived from this analysis and it is suggested that $\mathrm{CO}_{2}$ clusters may as well be present near the surface of Io.
\end{abstract}

\section{Introduction}

Io, a satellite of Jupiter, is the reddest object in the solar system and the first body (beyond Earth) where active volcanism has been observed. Io spectra show several features in the IR. While $\mathrm{SO}_{2}$ frost responsible for the prominent absorption features in this range, is one of the major surface components, the other components which are responsible for the weaker spectral features had been unidentified. We have focused our attention on the 2.02.5 and 2.9-5.3 $\mu \mathrm{m}$ regions. Originally unidentified bands falling at $2.97 \mu \mathrm{m}, 3.15 \mu \mathrm{m}$, $3.85 \mu \mathrm{m}$, and $3.91 \mu \mathrm{m} \mathrm{[1]} \mathrm{and} 2.1253 \mu \mathrm{m}[2,3]$, were found in Io spectra. All the features, except the $2.1253 \mu \mathrm{m}$ band, show strong temporal and longitudinal variations. In this paper, we present the result of comparative studies between observational data on Io $[1,2]$ and detailed laboratory studies of plausible surface ices $[1,3]$.

\section{Results}

Among the unidentified features of the Io spectrum, the $3.91 \mu \mathrm{m}$ and $3.85 \mu \mathrm{m}$ bands fall close to but not at the position expected for the $\mathrm{S}-\mathrm{H}$ stretching vibrations of pure $\mathrm{H}_{2} \mathrm{~S}$ frost; the 3.15 and $2.97 \mu \mathrm{m}$ pair fall close to those expected for the $\mathrm{O}-\mathrm{H}$ stretching vibrational modes of $\mathrm{H}_{2} \mathrm{O}$, and the $2.1253 \mu \mathrm{m}$ band falls close to, but not at the position of an overtone of the asymmetric stretching vibration of solid $\mathrm{CO}_{2}$. Laboratory simulations $[1,3]$ were then performed on pure $\mathrm{H}_{2} \mathrm{~S}$, pure $\mathrm{H}_{2} \mathrm{O}$, pure $\mathrm{CO}_{2}$ and pure $\mathrm{SO}_{2}$ frosts and their mixtures (mixed molecular ices and layered ices) in order to determine how the solid state interactions as well as temperature variations (from $9 \mathrm{~K}$ to $130 \mathrm{~K}$ ) and $\mathrm{UV}$ irradiation would affect the spectra. These comparative studies of spectra of Io with laboratory absorption spectra allow us to draw several main conclusions about the composition and physical nature of the surface material on Io.

1- The good match between the laboratory spectra and the spectra of Io strongly suggests that hydrogen sulfide is mixed in the surface material of the satellite [1]. An upper limit of about 3\% for the amount of $\mathrm{H}_{2} \mathrm{~S}$ relative to $\mathrm{SO}_{2}$ in the surface material is indicated at the cold patches $(\sim 100 \mathrm{~K})$. The $3.91 \mu \mathrm{m}$ and $3.85 \mu \mathrm{m}$ bands in the spectra of Io (Fig.1) indicate that 
$\mathrm{H}_{2} \mathrm{~S}$ is present as clusters and isolated molecules in a matrix of $\mathrm{SO}_{2}$. The laboratory experiments show that the infrared spectrum of $\mathrm{H}_{2} \mathrm{~S}$ embedded in an $\mathrm{SO}_{2}$ ice is largely unaffected by thermal variations below $100 \mathrm{~K}$ and prolonged VUV irradiation, implying that $\mathrm{H}_{2} \mathrm{~S}$ can survive the harsh conditions on Io which is in Jupiter's radiation belt. Also, only mixed molecular ices (i.e, $\mathrm{SO}_{2}$ matrices containing $\mathrm{H}_{2} \mathrm{~S}$ ) can explain the observed band shifts and splitting and can account for the fact that solid $\mathrm{H}_{2} \mathrm{~S}$ is observed in the surface material of Io under temperature and pressure conditions well above the sublimation point of pure $\mathrm{H}_{2} \mathrm{~S}$.

2- The relatively more complicated case of the variable bands of Io at $2.97 \mu \mathrm{m}$ and 3.15 $\mu \mathrm{m}$ indicates that traces of water are suspended in the mixtures of $\mathrm{H}_{2} \mathrm{~S}$ and $\mathrm{SO}_{2}$. An upper limit of about $0.1 \%$ for the amount of $\mathrm{H}_{2} \mathrm{O}$ relative to $\mathrm{SO}_{2}$ is implied [1]. The spatial and temporal variability of the $\mathrm{H}_{2} \mathrm{O}$ bands appears correlated with the volcanic activity on Io. 3- The experiments also suggest that the newly discovered band at $2.1253 \mu \mathrm{m} \mathrm{[2]} \mathrm{may} \mathrm{be}$ due to the formation of $\mathrm{CO}_{2}$ clusters in the atmosphere of Io. An upper limit of about $1 \%$ for the amount of $\mathrm{CO}_{2}$ relative to $\mathrm{SO}_{2}$ is derived and much of the $\mathrm{CO}_{2}$ is estimated to be contained in the cold $(\sim 100 \mathrm{~K})$ polar regions of the satellite [3].

This study stresses the importance of studying mixed ices (matrices) in carrying out laboratory simulations of the "dirty" ices covering the surfaces of satellites and planets in the solar system. Previous studies have only considered pure materials and neglected the importance of molecular interactions.

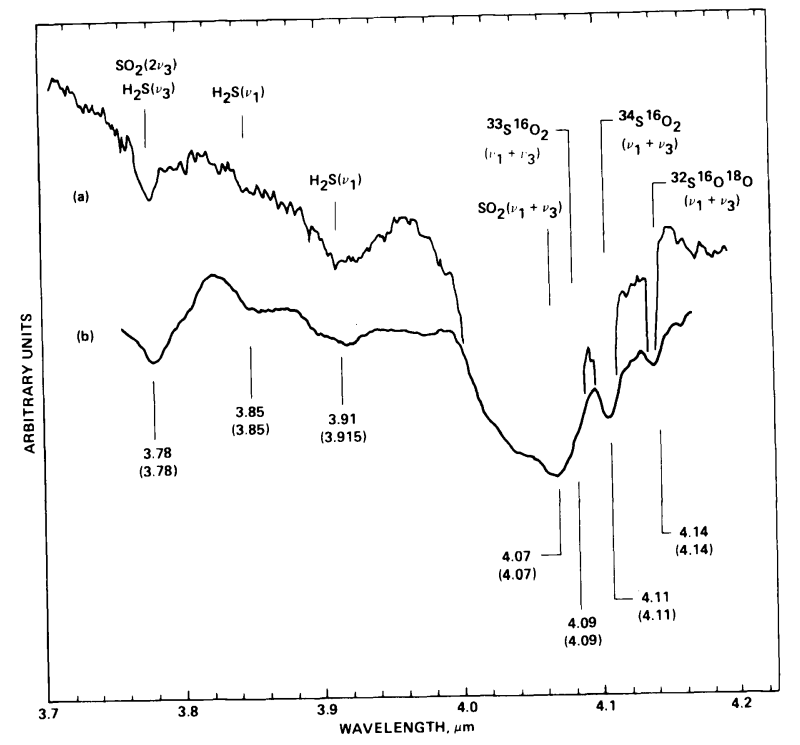

Figure 1: Comparison between (a) the IR absorption spectrum of an $\mathrm{H}_{2} \mathrm{~S}: \mathrm{SO}_{2}(3: 100)$ ice grown on a $100 \mathrm{~K}$ surface [1] and (b) the reflectivity of Io at $\Phi=70^{\circ}$ measured by Howell et al (Icarus 78, 27-37, 1989).

\section{References:}

1- Salama, F., Allamandola, L. J., Witteborn, F. C., Cruikshank, D. P., Sandford, S. A., and Bregman, J. D. (1990) 'The $2.5-5.0 \mu \mathrm{m}$ Spectra of Io: Evidence for $\mathrm{H}_{2} \mathrm{~S}$ and $\mathrm{H}_{2} \mathrm{O}$ Frozen in $\mathrm{SO}_{2}^{\prime}$, Icarus 83, 66-82.

2- Trafton, L. M., Lester, D. F., Ramseyer, T. F., Salama, F., Sandford, S. A., and Allamandola, L. J. (1991) 'A New Class of Absorption Feature in Io's Near-Infrared Spectrum', Icarus 89, 264-276.

3- Sandford, S. A., Salama, F., Allamandola, L. J., Trafton, L. M., Lester, D. F.,and Ramseyer, T. F. (1991) 'Laboratory Studies of the Newly Discovered Infrared Band at $4705.2 \mathrm{~cm}^{-1}(2.1253 \mu \mathrm{m})$ in the Spectrum of Io', Icarus 91, 125-144. 